\title{
Endocrine Disrupting Chemicals - Inducers of Epigenetic Gene Expression and Enhancers of Cell Death in Neurons
}

\section{Koji Shimoke $\mathbf{e}^{12^{*}}$}

${ }^{1}$ High Technology Research Core (HRC), Kansai University, 3-3-35, Yamate-cho, Suita, Osaka 564-8680, Japan

${ }^{2}$ Laboratory of Neurobiology, Department of Life Science and Biotechnology, Faculty of Chemistry, Materials and Bioengineering, Kansai University, 3-3-35, Yamate-cho, Suita,

Osaka 564-8680, Japan.

Endocrine disrupting chemicals (EDCs) exert estrogen-like effects that have various consequences in individuals. EDCs inhibit the effects of endogenous hormones by binding to the hormone receptor more tightly than the hormone itself. EDCs also accumulate in cells due to their chemical stability, and thus male genital organs treated with EDCs change to female-like organs. For example, crocodiles in Florida have been found to have an abnormally shortened penis, a decreased number of sperm, sterility, imperfect descent of the testicles and abnormal hypoplasia of sexual organs that all may be caused by EDCs [1]. EDCbound hormone receptors work as transcription factors in the nucleus, but the genes that induce phenotypic changes that influence germ cells are unclear. EDCs may also cause breast and prostate cancer by exerting estrogen actions and it has been suggested that EDCs can also influence the nervous system. p-Nonylphenol, an alkylphenol EDC produced from detergents in the environment, binds to estrogen receptor and has estrogen-like actions. This molecule is used as a plasticizer in plastics and as an antioxidant in polystyrene and polyvinyl chloride, and is found widely in the environment. This is a concern, since it has been shown that p-nonylphenol induces apoptosis in a trophoblast-derived choriocarcinoma cell line [2].

Apoptosis occurs in neurodegenerative disorders, including Alzheimer's, Parkinson's and Huntington's diseases [3]. The molecular mechanism of apoptosis consists of DNA fragmentation by nucleases after a caspase cascade is initiated by mitochondrial dysfunction and phosphorylation of stress kinases such as c-Jun N-terminal kinase (JNK) and p38 mitogen-activated kinase (p38MAPK), which belong to the MAPK family. A second type of apoptosis involves accumulation of unfolded proteins in the endoplasmic reticulum (ER) [4]. This phenomenon is referred to as ER stress, and apoptosis induced through this stress is termed ER stress-mediated apoptosis. Bisphenol A (BPA), another EDC, can induce ER stress-mediated apoptosis. This type of apoptosis involves genes such as glucose-regulated protein 78 (GRP78) and Nur77, which are thought to be expressed via an epigenetic mechanism of histone $\mathrm{H} 3$ modification to prevent ER stress-mediated apoptosis. Thus, a detailed functional analysis of each gene is necessary in a toxicological study of BPA.

\section{Research Support}

KAKENHI (25340104), SENRYAKU (2013-2017) and Kansai University Grant-in-Aid for Encouragement of Scientists (2014).

\section{References}

1. Guillette LJ Jr, Pickford DB, Crain DA, Rooney AA, Percival HF (1996) Reduction in penis size and plasma testosterone concentrations in juvenile alligators living in a contaminated environment. Gen Comp Endocrinol 101: $32-42$.

2. Bechi N, letta F, Romagnoli R, Focardi S, Corsi I, et al. (2006) Estrogenlike response to p-nonylphenol in human first trimester placenta and BeWo choriocarcinoma cells. Toxicol Sci 93: 75-81.

3. Rao RV, Bredesen DE (2004) Misfolded proteins, endoplasmic reticulum stress and neurodegeneration. Curr Opin Cell Biol 16: 653-662.

4. Kaufman RJ (2002) Orchestrating the unfolded protein response in health and disease J Clin Invest 110: 1389-1398.
*Corresponding author: Dr. Koji Shimoke, Tel: +81-6-6368-0853; Fax: +81-66330-3770; E-mail: shimoke@kansai-u.ac.jp

Received: November 08, 2015; Accepted: November 09, 2015; Published November 30, 2015

Citation: Shimoke K (2015) Endocrine Disrupting Chemicals - Inducers of Epigenetic Gene Expression and Enhancers of Cell Death in Neurons. J Bioengineer \& Biomedical Sci 6: e122. doi:10.4172/2155- 9538.1000e122

Copyright: @ 2015 Shimoke K. This is an open-access article distributed under the terms of the Creative Commons Attribution License, which permits unrestricted use, distribution, and reproduction in any medium, provided the original author and source are credited. 